\title{
Cultura, violencia y dignidad en América Latina. Notas introductorias
}

JUlio MEJÍANAVARRETE

\section{RESUMEN}

En este artículo pretendemos desarrollar algunas cuestiones iniciales que permitan organizar el debate sobre la cultura de la violencia y la emergencia de la cultura de la dignidad en América Latina.

PALABRAS CLAVE: cultura de la violencia, cultura de la dignidad, consumismo, razón cínica, individualismo.

Culture, violence and dignity in Latin America.

\section{Introductory notes}

\section{ABSTRACT}

In this article we develop some initial questions that organize the debate on the violence's culture and the emergence of dignity culture's in Latin America.

KEYWORDS: violence's culture, dignity's culture, consumerism, cynical reason, individualism. 


\section{Introducción}

a violencia y sus expresiones culturales se han extendido de modo considerable como resultado de la modernización global en América Latina. Sin embargo, en las últimas décadas irrumpe inéditas formas culturales fundadas en la dignidad, en la fuerza de los valores de la libertad y la igualdad social.

En ese sentido, pareciera que el conflicto cultural define el ritmo de la vida social contemporánea de América Latina. Emerge una nueva forma de subjetividad que pone en cuestión lentamente las formas dominantes de pensar de la sociedad.

Sigmund Freud en El malestar de la cultura (1930) formuló una interrogante fundamental sobre la dinámica civilizatoria que cobra vigencia inusitada en la actualidad. El desarrollo cultural era entendido como una transacción entre seguridad y libertad, los contemporáneos de Freud estaban dispuestos a ceder seguridad para obtener más libertad. De esa forma, la historia era vista como el desarrollo de la búsqueda de mayor libertad, de la propagación de la cultura de la libertad. En la actualidad todo se ha modificado, las gentes estarían dispuestas a ceder parte de la libertad a costa de librarse del aterrador espanto de la inseguridad existencial, la demanda de mayor seguridad por el crecimiento exponencial de violencia. La historia reciente, de las últimas décadas, puede ser expuesta como el avance de la petición de más seguridad.

En este artículo pretendemos desarrollar algunas cuestiones iniciales que permitan organizar el debate sobre la cultura de la violencia y la emergencia de la cultura de la dignidad en América Latina. El artículo se divide en cuatro partes. La primera sección expone las condiciones sociales de la violencia, destacamos la relación entre la modernidad tardía y el incremento delictivo en América Latina. La segunda describe una cultura oscurantista que conlleva a la hegemonía del individualismo extremo, la "razón cínica" y el consumismo que condicionan el desarrollo de las conductas violentistas en América Latina. La tercera parte resalta la incidencia de los movimientos de la sociedad que instituyen los valores de libertad e igualdad social. Finalmente, se expone la emergencia de la cultura de la dignidad en América Latina.

\section{Sociedad y violencia}

El actual proceso cultural se encuentra definido por el momento de transformaciones profundas del patrón moderno global. Wallerstein (2001) define a las primeras cinco décadas del siglo XXI como un momento de transición, en que las tendencias seculares se alejan del equilibrio y entran en un estado de bifurcación e incertidumbre societal. El sistema-mundo moderno después de más de 500 años ha entrado en un

\section{6/ REVISTA DE SOCOLLOGíA 26}


período de fluctuaciones rápidas y constantes. La modernización capitalista global como nunca en su historia está expandiéndose a un ritmo exponencial y por primera vez una formación social cubre todos los rincones del planeta. Período abierto desde la mitad de la década del setenta que viene produciendo cambios estructurales en la organización de la sociedad. En ese sentido, la dinámica de las mutaciones de la globalización no solo significan efectos coyunturales en la dinámica de la modernidad, sino más bien implica su misma reconstrucción, Quijano $(2014 a, 852)$ denomina a este nuevo período histórico de "crisis raigal de la colonialidad global del poder".

En particular, el desarrollo de la sociedad moderna global se correlaciona con la gestación de una nueva revolución tecnológica, que empieza modificarla. La expansión exponencial del capital determina una situación de amenaza creciente de la naturaleza, llevando el conflicto a niveles catastróficos entre una acumulación ilimitada del capital frente a los recursos definidos de la tierra, el resultado: la crisis climática global que pone en peligro la propia vida. En los andes peruanos se ha perdido irremediablemente el $42.64 \%$ de los glaciares de las cordilleras por la impacto del calentamiento global (MINAGRI-ANA 2014). Actualmente está en desarrollo la sexta extinción a gran escala de la vida en la tierra, la ratio es hasta 100 veces más alto que la tasa natural (Ceballos et al. 2015) y el año 2015 ha sido el de mayor temperatura de los que se tiene registro histórico (NASA 2015). Parecería que el equilibrio autopoiético de la Tierra se ha roto por la influencia depredadora de la modernización de los últimos cinco siglos, poniendo en peligro toda forma de existencia en los próximos 100 años.

El desarrollo de la automatización implica un cambio decisivo en la sociedad, pareciera que la relación capital-asalariado llega a su límite, el capitalismo ya no puede reproducir masivamente trabajo asalariado, genera cada vez más precarización, flexibilidad laboral y desempleo estructural, aunque el sistema puede seguir reproduciéndose bajo la dominación de la pequeña producción mercantil y de otras que lindan con formas para-esclavistas y serviles ${ }^{1}$. La consecuencia es el crecimiento incesante de la desigualdad social (Castells 2015), América Latina sigue siendo el continente de mayor disparidad social, en el mundo el $10 \%$ de la población se apropiada del $88 \%$ de la riqueza y el $50 \%$ más pobre posee únicamente el $1 \%$ del total. En otros términos, el sistema no puede seguir controlando a la población por medio de relaciones asalariadas y de forma directa en el control del cuerpo y de las propias personas en los principales panópticos de la modernidad. La modernidad global se desplaza hacia la dominación de la subjetividad y el control de las mentalidades.

1 En el Perú este proceso se expresa crudamente en que el $70 \%$ de los trabajadores se encuentran en el sector informal. Realidad que afecta a los países desarrollados, en Francia el 25\% de personas menores de 25 años se encuentran desempleadas y en España los datos se acercan al $50 \%$ de los jóvenes. 
En general, la «crisis raigal» de la modernidad global traza una posibilidad funesta de la historia, escenario que no permite tener la esperanza de erradicar la miseria humana, ni liberar el sufrimiento de la humanidad. Al contrario, la promesa de la modernidad ha sido incumplida en América Latina y el mundo, más bien pareciera que marchamos a una expansión de la modernidad pero sin los grandes logros que el modernismo trazó originariamente, una modernización sin precedentes del planeta aunque sin las aspiraciones libertarias de la modernidad.

La violencia se han transformado en parte central de la vida cotidiana. Las conductas violentistas no pueden ser comprendidas como simples problemas individuales, de la misma forma, no puede ser entendidas solo con argumentos de situaciones de pobreza y carencias de servicios sociales (Tavares dos Santos y Barreira 2016). La violencia y el delito se tornan estructurales, se transforma en componentes del patrón moderno globalizado. Situación de incremento constante de la violencia que se vincula estrechamente con la expansión del crecimiento económico en América Latina (PNUD 2013, 19), paralelamente todos los índices de delito, violencia y percepción de inseguridad se han desbocados inconteniblemente.

Todos los aspectos de la existencia social se encuentran teñidos y corroídos por la violencia y la cultura de la agresión. El mundo se vuelve un lugar inhabitable, el delito y la violencia son amenazas a la vida, a la integridad física y patrimonial de las personas, que a su vez conllevan un sentimiento de temor, amenaza y vulnerabilidad frente al peligro.

\section{Cultura violentista}

La cultura de la violencia considera que la fuerza es la única forma para resolver los conflictos y disputas entre las personas y grupos sociales. La violencia se naturaliza, se considera que es el medio normal y la única manera de resolver las diferencias sociales. No se trata solo de un pensamiento de los sujetos involucrados en actos de violencia, corresponde más bien a una cultura que es la expresión del orden neoliberal, pensamiento que condiciona y empuja a la violencia y agresión en la sociedad globalizada contemporánea.

La cultura moderna reproduce "la irracionalidad de lo racionalizado", donde las relaciones mercantiles amenazan la vida humana y la naturaleza, se transforma en la condición de la "muerte colectiva". En América Latina la modernidad global produce irracionalidad dado que la razón instrumental medios-fin está llegando a su límite y entra en un dinámica de crisis, no solo explota y domina, sobre todo, ahora destruye la naturaleza y "destruye al otro excluyendo grandes poblaciones", el

\section{8/ ReVISTA DE SOCIOLOGÍA 26}


sistema social genera principalmente "violencia más allá de todo cálculo"y muerte permanente (Hinkelammert 2015, 67-133). La cultura de la violencia expresa un mundo donde predomina el individualismo extremo, el desarrollo de la cultura cínica y el consumismo que corroen la energía colectiva, la confianza y la vida comunitaria (Mejía 2015).

En la modernidad global la propagación del individualismo disperso estimula la mercantilización de la subjetividad, el sujeto atomizado pasa a ser el núcleo sobre el cual gira toda la vida social en América Latina. El sujeto se ha librado de los últimos constreñimientos estructurales socializantes que impedían su total emancipación: la disminución del peso social del Estado, de las clases sociales, del poder de la vecindad, la familia, las grandes ideologías dejan de ser vehículos de proyectos históricos, las creencias utópicas se desacreditan, pareciera que se desarrolla una sensación de "era del vacío" (Lipovetsky 2003), se han evaporado los constreñimientos sociales y éticos del individualismo en la sociedad global. Hay un deterioro constante de los vínculos sociales, de las solidaridades y, al mismo tiempo, hay un proceso de atomización, los comportamientos tienden a aislar a las personas. En general, la sociedad se define por el "egocentrismo, que reduce el horizonte al interés personal" (Morin 2011, 57), la vida social gira en torno del individuo.

La cultura de privatización y el individualismo extremo ocurren en un mundo de incesante violencia y destrucción del "capital social" (Bourdieu 1980), donde el afecto y la confianza con los otros resultan disfuncionales para la sociedad y se pierde la energía colectiva que puedan generar las interacciones de respeto, disfrute de la compañía de los otros y la fortaleza de la comunidad. La sociedad globalizada privatiza y mercantiliza, separa a los individuos y hace que las emociones con los demás se transformen en mercancía.

El abandono del compromiso emocional con los demás, no desemboca en un individualismo absoluto, sin vínculos sociales, más bien genera que las personas conciban los vínculos entre ellos en términos puramente mercantiles, interesa solo la búsqueda del beneficio exacerbado de las relaciones con los otros. Las interacciones sociales pierden su contenido emocional y se convierten en puros compromisos. La modernidad neoliberal reestructura el imaginario social, la vida cotidiana, los valores y lleva que la vida de las gentes se oriente por "considerar superflua toda ley civil o moral" (Tododrov 2014, 77). El otro solo existe como un obstáculo o un medio en el camino de la búsqueda del éxito personal, la cultura transforma los vínculos entre las personas en relaciones puras sin frenos sociales ni morales, sin límites ni regulaciones. Un orden simbólico que que concibe la vida social en función de la agresividad individualista, que pretende acostumbrar y socializar a la población en la violencia. 
El desarrollo del individualismo, la devastación del capital social y la destrucción de la confianza trae su sustitución por el cinismo². La modernidad global desarrolla una cultura cínica que no tiene el tapujo de aceptar abiertamente lo que antes ocultaba, la injusticia, violencia, corrupción y falta de humanidad, desecha todo sentimiento de culpa al borrar el sentimiento de dolor que provocaba la idea de haber perjudicado a los otros (Bauman y Donskis 2013). Se intensifica el crecimiento económico descomunalmente $y$, a la vez, descaradamente no importa destruir la naturaleza y las personas. En la vida social pareciera que se extiende el influjo del "todo vale" que deriva en el comportamiento cínico, el individuo busca imponerse porque piensa que tiene todo el derecho de hacerlo, sin pensar en los otros e incluso apelando a la violencia desembocada (Ubilluz 2006, 74-75). La afirmación de que "nadie cree en nadie" parece haberse convertido en el principio central para salir adelante, el recurso de la violencia se impone en la lucha de la vida diaria. El cinismo y la violencia son la otra cara del hiperindividualismo globalizado.

La generalización de la razón cínica en la modernidad global es la preponderancia del "estado de guerra" (Dussel 2002-2003) entre las personas, la excepcionalidad de la beligerancia y la violencia se convierten en parte intrínseca de la vida en América Latina, es el reino del enfrentamiento de individuos egoístas, en la que el otro es aniquilado, vencido a cualquier precio. En el "estado de guerra" la sociedad se vuelve un conjunto de agresivos egos que compiten con la finalidad suprema de autopromoverse a costa de los demás, en la que predomina el ventajismo individual, el afán de lucro desbocado, la rudeza y el pragmatismo que llega a su forma de descarada e indolente, sin importar nada. Es la negación de todo derecho del otro sin reparo y miramiento alguno. El estado de guerra_enajena la moral, despoja a las instituciones y a la vida social de las obligaciones que condicionaban la actuación de las personas según la familia, la comunidad y los ideales utópicos. Simplemente la vida social se transforma en la práctica de vencer por todos los medios e imponer los intereses privados y egoístas sin pensar que algo se interpone.

El cinismo es el uso del poder absoluto, arbitrario y sin límites, simplemente los demás, las gentes no interesan, es el dominio de la cultura de la desesperanza, del "sálvese quien pueda" y el "después de nosotros el diluvio" (Hinkelammert 2001,105-111). El cinismo se revela como la forma moderna global de reproducción de la inferiorización de las gentes por medio de la fuerza, desde la conducta individual hasta las prácticas de dominación de las corporaciones y los países, que someten y

2 Los orígenes del cinismo se remontan a la Grecia antigua, expresada en la escuela filosófica liderada por Antístenes, que reivindicaba la vida natural, sin normas, ni convenciones, aspiraba a una existencia sobria, sin ornamentos, ni artificios y se buscaba la autenticidad. Contario al cinismo difuso de la modernidad tardía. Vease Sloterdijk (2003).

\section{0/ REVISTA DE SOCOLLOGíA 26}


controlan apelando a prácticas directas, desvergonzadas y descaradas, sin un mínimo de remordimiento moral: la trata de blancas, el trabajo infantil, el trabajo precario, las nuevas formas esclavizadas del trabajo, hasta las guerras de sometimiento de las poblaciones. La "razón cínica" permite la estructuración societal de la desigualdad extrema sin que nadie se inmute y conmueva, está permitido el "todo vale" sin pena y escrúpulo. Es la cultura oscurantista de la época de la globalización.

Otro aspecto central de la cultura de la modernización global que induce a la violencia es el consumismo. El consumismo viene apropiando de los resortes centrales del mundo social en los países de América Latina (Mejía 2014), señala un paraíso de mercancías y muestran que todas y cada una de las personas pueden acceder a todo tipo de bienes y mercancías, estimulan al máximo los apetitos consumistas. Pero, para las grandes mayorías, especialmente los jóvenes, los mecanismos que proporcionan la sociedad son insuficientes o nulos para alcanzar el mundo de productos deseables, al contrario se expande la la exclusión, marginación y precariedad social. La violencia pareciera encontrarse enmarcada por la tensión aguda entre la modernización globalizada de América Latina y las demandas sociales crecientes de la población. Este conflicto entre las expectativas crecientes de la población y los modos inestables que la sociedad ofrece para alcanzarlos genera una tensión aguda en la estructura social que incita el desarrollo de formas de desviación. La Teoría de la "Tensión Cultural" (Merton 1972) explica que las formas de trasgresión de las normas sociales del comportamiento adquiere toda su fuerza para comprender las conductas violentistas.

Los medios de comunicación llevan esta contradicción a situaciones extremas, se muestra que se puede alcanzar el bienestar y la abundancia, al mismo tiempo, las oportunidades para lograr y realizar las expectativas y aspiraciones en nuestra sociedad son muy limitadas y excluyentes. El resultado es la frustración, resignación, rechazo y, además, acentúa la conciencia de ser un grupo social marginado, que no tiene las herramientas disponibles de la sociedad para acceder o realizar sus expectativas. Los medios de comunicación refuerzan el sentimiento de privación, al comparar las carencias y necesidades con la situación de abundancia de recursos y mercancías que muestra la sociedad. Hannah Arendt (1979) decía que la actitud al culto a la fuerza y la prédica de la agresión brota cuando se convierte en abierta negación a los valores fundamentales de la sociedad, cuando cobra sentido en los individuos las carencias y necesidades no satisfechas. En un contexto de tensión social, los medios de comunicación crean las condiciones para que se reaccione con furia cuando se ofrece un mundo extremadamente desigual, al que no pueden acceder las mayorías y solo está abierto para ciertos sectores minoritarios.

Como las oportunidades legítimas para alcanzar metas y expectativas que incita la cultura son limitadas o no existen, los medios de comunicación educan en 
una identificación con las imágenes y símbolos basados en la violencia, la ruptura de normas sociales y la predisposición de conductas basadas en el delito. El predominio de la atomización social, aislamiento, la falta de oportunidades legítimas para desarrollarse y realizar las expectativas culturales de la sociedad dominante, posibilita el desarrollo de la violencia. Se desarrolla un pensamiento basado en pautas, valores pro violentistas y actividades ilegales, se expande la cultura de las oportunidades ilegitimas que permiten violar las leyes y normas de conducta para alcanzar las necesidades y expectativas. En esas condiciones, pareciera que es cierta la afirmación de Giovanni Sartori $(1998,37)$ que los medios de comunicación crean un "modelo excitante y tal vez triunfador de vida", proporciona el mecanismo para lograr las expectativas y realización por medio de la violencia. Proporciona un modelo de vida en su relación con la sociedad, basada en la transgresión y violación de la norma y leyes vigentes.

En América Latina la violencia es la ética del orden global, donde el poder del individuo egoísta se impone y no interesa los otros, la humanidad y la naturaleza. Es el poder absoluto y arbitrario de la razón cinica del todo vale y de un mundo donde predomina el consumismo, para lo cual se puede recurrir a la fuerza, no interesa la ley y menos la "moralidad" es el poder del "estado de guerra" de los más fuertes y agresivos.

\section{Movimientos de la sociedad}

En el contexto de cambios sistémicos, son los nuevos movimientos de la sociedad los que vuelven a instituir valores culturales libertarios que cuestionan el patrón epistémico moderno, alternando las formas de pensamiento de la sociedad sobre sí misma, germinando un nuevo sentido histórico que empieza a revisar la subjetividad de la violencia, trayendo una nueva propuesta ideal del orden societal, que prescribe un rumbo alternativo y alumbra la vida interior de las personas. Procesos que trazan la aspiración societal que pueda constituirse con las máximas de justicia societal, libertad y autonomía (Mejía 2016).

Los movimientos sociales señalan un nuevo sentido histórico a contracorriente de la dominación, explotación y desigualdad del mundo actual. Pareciera que los nuevos movimientos de la sociedad anuncian la posibilidad de un "tiempo-eje" de grandes modificaciones culturales, semejante al de los siglos VIII y V a. c. que posibilitaron el surgimiento en múltiples espacios del mundo de Confucio en la China, el Budismo en India y el desarrolla el pensamiento griego que fundaran el pensamiento especulativo actual (Jaspers 1968). 
En las últimas décadas se ensayan diversas respuestas en América Latina. Indígenas, afros, negros, etnicidades y grupos sociales diferenciados y subordinados cuestionan la idea de la raza, etnicidad y formas de clasificación y jerarquización social. Poblaciones y comunidades se enfrentan a la mercantilización del territorio y la ecología para plantear la defensa de las condiciones de existencia y sobrevivencia del mundo. Las redes de "indignados" que se extendieron desde la primevera árabe, los indignados europeos, el movimiento "occupy" en Estados Unidos, los movimientos estudiantiles de Chile, \#Yosoy132 de México, las protestas del Brasil, "rebelión de los pulpines" en el Perú instalan las demandas de igualdad social como la aspiración central frente al "1\% más rico" de la sociedad ${ }^{3}$. De la misma forma, trabajadores, mujeres, jóvenes, homosexuales, pacifistas, anti-utilitarios, antiglobalización y otros desarrollan un conjunto de idearios, demandas y medidas de lucha que apuntan al reconocimiento de los derechos humanos, de los derechos las mujeres, de los derechos de los homosexuales, de los derechos de la paz, solidaridad, reciprocidad y, en general, a la construcción de una sociedad más igualitaria y justa.

Los movimientos de la sociedad son la fuerza central de la transformación contemporánea que posibilitan a la diversidad de actores su conversión en sujetos sociales con autonomía y proyectos nuevos que permitan modificar las lineas maestras de la vida social, al margen de las instituciones existentes. Se abre un momento histórico de transformación colosal de la cultura, pierde legitimidad el viejo constructo mental sobre las desigualdades racial/étnica, de género, de clases y de la degradación de la tierra, siempre justificadas por la naturalización de la superioridad del talento de ciertos individuos sobre las mayorías y de lo humano sobre la tierra, que los hacen distintos, especiales y superiores, se cuestionan las viejas formas categoriales que facilitan el pensar y organizar históricamente el orden existente del mundo en una cultura de la desigualdad (Bauman 2014, 83-91).

En América Latina desde fines del siglo XX por la crisis de la modernidad globalizada y el desarrollo de los nuevos movimientos de la sociedad, empieza a cambiar el sentido del orden y las mentes de las personas ponen en parentesis los fundamentos de la legitimidad de la desigualdad social, la legitimidad de la idea de la raza/etnicidad, la legitimidad de la idea de género y la legitimidad de la cosificación de la naturaleza, instituyen valores, ideas y la emergencia de una subjetividad que impugna el subterfugio de la naturalización de toda forma de desigualdad social y afirman posibilidades de imaginar un mundo instituido en la igualdad social de las gentes y en la unidad de la sociedad con el universo.

3 Puede consultarse Castells (2014), Zibechi (2015), Sandobal, R. (2015), Rojas (2012), Fernández-Maldonado (2015). 


\section{Cultura de la dignidad}

El devenir del sistema mundial moderno global está generando un campo de disputa cultural muy intenso. Se ha abierto una etapa de modificaciones del pensamiento moderno en América Latina. La vieja "cultura de la dominación" y de la violencia se encuentra en una etapa de cuestionamiento por el desarrollo de una cultura de la dignidad. Es una etapa de emergencia epistémica que contradicen la hegemonía del pensamiento neoliberal.

La crisis del sistema moderno global y los movimientos de la sociedad en América Latina están llevando a la pérdida de legitimidad de la desigualdad social, cuyos argumentos ya no se aceptan. Lo típico de estos movimientos de la sociedad es la disputa por la dignidad, surgen contra la humillación de ser diferente, no solo de ser explotado, reprimido y oprimido, sino por la negación de la integridad de ser humano, de su privación de humanidad (Bauman y Bordoni 2016). Aparece una nueva sensibilidad dotada de dignidad, todos tenemos la misma dignidad común, lo humano no reside en lo especial y diferente naturalizado sino en la idea esencial de la igualdad social. En América Latina la cultura de la violencia empieza a perder direccionalidad y hegemonía en las formas de pensamiento, la subjetividad está produciendo otros modos de percibir la realidad, otros modos de imaginar un mundo fundado en la justicia social y libertad de las personas más allá de la propia modernidad. En América Latina, la emergencia de las poblaciones sometidas e indigenizadas por la colonialidad abren un nuevo horizonte epistémico alternativo al eurocéntrico, asume la conciencia de pertenecer a un solo pueblo la humanidad, cuyo principio esencial es la dignidad (Quijano 2015).

Dinámicas que se despliegan en los margenes del sistema moderno y de colonialidad por los movimientos de la sociedad y experiencias inéditas de vida social que buscan restituír la vida de los sujetos en relaciones solidarias y de identidad con el planeta como la única forma de enfrentar las relaciones de explotación y dominación que llevan a la destrucción y muerte del ser humano y de la naturaleza. Los movimientos de la sociedad son las fuentes de movilizaciones y transformaciones sociales, rescatan la memoria histórica de las culturas amerindiandias y generan "utopías reales" ${ }^{\prime 4}$ que cambian los valores y mentalidades de las personas que buscan desarrollar originales formas de vivir, nacientes identidades, enuncian proyectos autónomos de organización a partir de principios lbertarios comunes que traducen las aspitaciones de una sociedad mejor, más allá de la propia acción de la mercanti-

4 Desarrollan experiencias de "utopías reales" $y$ "de coste marginal cero" fundadas en relaciones sociales "democráticos igualitarios" que se desenvuelven híbridamente en el mercado y fuera del mercado, véase Erik Olin Wright (2014) y Jeremy Ryfkin (2014).

\section{4/ RELUSTA DE SOCOLOOGÍA 26}


lización, del Estado y la violencia. En este sentido, el gran conflicto es cultural, frente a la mentalidad conservadora se desarrolla la idea de la dignidad que controvierte la injusticia, la humillación de la negación de los derechos humanos y traza la esperanza de una nueva sociedad cimentada en la igualdad.

De modo específico, en América Latina se inicia un proceso de relativización del constructo conceptual de la idea de la raza que sustentó por más de 500 años la dominación social y la negación de la ciudadanía a la mayor parte de la población por su pretendida condición natural de ser individuos pertenecientes a las "razas inferiores". Es a partir de la Segunda Guerra Mundial, con la derrota del nazismo y el militarismo japonés, que se inaugura el proceso de deslegitimación de la dominación basada en torno el racismo y, en especial, luego de las acciones de organización y movilización de la población indígenas de la región después de Chiapas en enero de 1994 por el cuestionamiento de toda forma de desigualdad social (Quijano 2014b).

Los movimientos de la sociedad en su defensa del territorio y la ecología bosquejan en América Latina una cultura fundada en la dignidad que comprende lo humano como componente intrínsico de la naturaleza, que implica la recuperación cultural de su animalidad, de constituir una especie, una en particular, de constituir un ser vivo dentro de la infinita existencia heterogénea de la tierra y del universo. La dignidad proyecta un ideal que invalida la diferencia y superioridad humana, nos devuelve al mundo natural y define a todos como seres mortales e igualitarios. Los humanos tenemos que pensarnos como una especie más y común de la naturaleza para enfrentar los graves problemas que amenazan el planeta (Leff 2004, 124-185). Un imaginario humano que resalta le valor de la igualdad en el mundo de la vida de la naturaleza.

Los movimientos de mujeres en América Latina en los últimos cincuenta años han transformado la conciencia sobre sí mismas (Luna 2004). Las mujeres tanto individual y colectivamente, aunque el patriarcado no ha desaparecido, ya no se piensan como objetos sino como sujetos con imaginarios basados en relaciones de igualdad social y de dignidad de ser reconocidas como seres humanos con derechos. El sentimiento de dignidad se va apoderando del pensamiento de las gentes y las relaciones hombre y mujer en todos los ámbitos de la vida social se alteran y empiezan a reconstruirse en terminos de los valores de igualdad social y la libertad.

Los movimientos estudiantiles y juveniles, de modo específico en Chile, Brasil, México y el Perú, cuestionan las relaciones de dominio, explotación y procuran formas de igualdad social. Experiencias colectivas que demandan ser identificados como sujetos de dignidad, frente a la humillación y negación de los derechos de personas, siempre apuestan por los sueños de un mundo de igualdad social. Pero lo más importante, comienzan a transformar drásticamente las relaciones de paternidad, tradicionalmente fundadas en la autoridad suprema de origen biológica, por ser el 
padre que engendra. Hoy la paternidad se ha convertido en un hecho moral, el hijo solo obedece y acepta la autoridad legitima del padre cuando viene acompañada de la confianza, el prestigio y la igualdad. La paternidad muestra el avance del valor de la igualdad en la sociedad del siglo XXI.

Los nuevos movimientos en redes que recorren el planeta, desde América Latina (Castells 2012), el norte del África, Europa y los Estados Unidos, instalan demandas de igualdad social como la aspiración central frente a la extrema polarización social del mundo neoliberal, graficado en el "1\% más rico" que se apropia del $99 \%$ de la riqueza global. Movimiento en redes que viene produciendo un cambio fundamental en las mentalidades de las gentes sobre la indignidad de la inmensa diferenciación social, la mayor de la historia humana, y desarrollan nuevos valores y juicios en torno a la dignidad humana, de un imaginario ide igualdad y justicia social.

En América Latina nuevamente se recrean valores de igualdad social que posibilitan la irrupción de otra episteme, traduciendo el desarrollo de un horizonte de sentido histórico alternativo. Hoy se bosqueja un inédito proceso cultural como parte inmanente de su encuentro con las ideas de igualdad social. Bauman (2014) lo expresa claramente "Si preguntáramos a la gente por los valores más importantes para ellos, es muy probable que muchos contesten nombrando la igualdad".

En general, la nueva cultura histórica de la dignidad emerge como nuevo sentido societal fundamentada en una responsabilidad y solidaridad entre nosotros y la naturaleza de una totalidad diversa, además de reconocer el comportamiento particular de los seres humanos. La dignidad es el valor que representa los derechos y la igualdad social de las personas.

La cultura de la dominación y violencia está en cuestión en Latinoamérica, se desarrollan formas de pensamiento originales, ya no parten de la justificación de las desigualdades sociales, empiezan a germinar discursos epistémicos alternos y se abren a un proceso de descolonialidad de la cultura. La emergencia epistémica facilita ir más allá de los límites de la modernidad y la colonialidad, la memoria y la imaginación hilvanan una posibilidad de existencia social diferente. Es en América Latina donde empieza ha desarrollarse la epistémica que cuestiona el modo de pensar europeísta, porque es el espacio primero y de fundación del proceso histórico del sistema de modernidad global (Quijano 2015, 15-20).

\section{Conclusión}

La modernidad se apertura con el debate sobre la dignidad y, pareciera, que llega a sus límites con el mismo debate. En efecto, en los albores de la modernidad Giovanni 
Pico Della Mirandola escribió su famoso Discurso sobre la dignidad del hombre (1486), rescatando la autonomía de lo humano y la igualdad de derechos. En la actualidad, en momentos de la mayor desigualdad de la historia de la humanidad y, probablemente, en los desenlaces y cuestionamientos de la modernidad recuperamos el Discurso sobre la dignidad, los seres humanos somos partes de la naturaleza, somos un solo pueblo y la dignidad es el mayor valor de la igualdad social.

La cuestión central sobre la vida social formulada por Freud en el tiempo presente adquiere un contenido diferente. Se trata de un momento de grandes cambios societales, aunque predomine en las últimas décadas la cultura de la búsqueda de la seguridad, hoy el conflicto cultural esencial gira entre la cultura de violencia y cultura de la dignidad que marca todo el escenario contemporáneo.

El discurso de la dignidad empieza a corroer los cimientos del modo de organización de la sociedad en torno a las jerarquías sociales y posibilita pensar en el largo plazo en un nuevo horizonte histórico que imagine una sociedad estructurada según los principios de la libertad e igualdad social.

\section{Referencias bibliográficas}

ARENDT, H. (1979). Sobre la violencia. México: Cuadernos de Joaquín Moritz.

BAUMAN, Z. (2014). ¿La riqueza de unos pocos no beneficia a todos? Bogotá: Paidós.

BAUMAN, Z. y BORDONI, C. (2016). Estado de crisis. Bogotá: Paidós.

BAUMAN, Z. y DonsKIS, L. (2013). Cegueira moral. A perda da sensibilidades na modernidade líquida. Río de Janeiro: Zahar.

BouRdIEU, P. (1980). "Le capital social. Notes provisoires", Actes de la Recherche en Sciences Sociales, Vol. 31, http://www.persee.fr/web/revues/home/prescript/article/arss_03355322_1980_num_31_1_2069

CASTELLS, M. (2012). Redes de indignación y esperanza. Los movimientos sociales en la era de internet. Madrid: Alianza.

CASTELLS, M. (2015)."Sociedades polarizadas", La Vanguardia, 17 de octubre: Barcelona, http:// www.caffereggio.net/2015/10/17/sociedades-polarizadas-de-manuel-castells-en-lavanguardia/

Ceballos G.; Ehrlich, P. R.; Barnosky, A.; Andrés García, A; Pringle, R. M. y Palmer, T. M. (2015) "Accelerated modern human-induced species losses: Entering the sixth mass extinction", Science Advances, Vol. 1, № 5, http://advances.sciencemag.org/content/advances/1/5/ e1400253.full.pdf

DusSEL, E. (2002/2003). “Estado de guerra” permanente y razón cínica, Revista Herramienta, № 21: Buenos Aires. 
FERNÁNDEZ-MALDONADO, E. (2015). La rebelión de los pulpines. Jóvenes, trabajo y política. Lima: Otra Mirada.

FREUD, S. (2010). El malestar de la cultura. Madrid: Alianza.

HINKELAMmeRT, F. (2001). El nihilismo al desnudo. Los tiempos de la globalización. Santiago: LOM. HinkelammeRT, F. \& MORA, H. (2005). Hacia una economía para la vida. San José: DEl.

HinKelammeRT, F. (2015). Solidaridad o suicidio colectivo. San José: Arlekín.

JASPERS, K. (1968). Origen y meta de la historia. Madrid: Revista de Occidente.

LEFF, E. (2004). Racionalidad ambiental. La reapropiación social de la naturaleza. México: Siglo XXI. LIPOVETSKY, G. (2003). La era del vacío: ensayos sobre el individualismo contemporáneo. Madrid: Anagrama.

LUNA, L. (2004). Los movimientos de mujeres en América Latina y la renovación de la historia. México: fem-e-libros.

MEJíA, J. (2016). América Latina, modernidad y conocimiento. El desarrollo de otro discurso epistémico. Lima: Facultad de Ciencias Sociales UNMSM.

MEJÍA, J. (2015). “Corrupción, violencia y cinismo. Notas sobre la insensibilidad moral en el Perú", en Ledesma, M. Justicia, derecho y sociedad. Debates interdisciplinario para el análisis de la justicia en el Perú. Lima: Tribunal Constitucional del Perú.

MeJíA, J. (2014). Sociedad, consume y ética. El Perú en tiempos de globalización, Facultad de Ciencias Sociales Lima: UNMSM.

MERTON, R. (1972). Teoría y estructura raciales. México: FCE.

MORIN, E. (2011). La vía. Para el futuro de la humanidad. Barcelona: Paidós.

NASA (2015). NOAA Analyses Reveal Record-Shattering Global Warm Temperatures in 2015, http://www.nasa.gov/press-release/nasa-noaa-analyses-reveal-record-shattering-globalwarm-temperatures-in-2015

Pico della Mirandola, G. (2006). Discurso sobre la dignidad del hombre. Medellín: Editorial $\pi$.

PNUD (2013). Informe Regional de Desarrollo Humano 2013-2014. Seguridad ciudadana con rostro humano: diagnóstico y propuestas para América Latina. Nueva York: PNUD.

QuIJANO, A. (2015): “Notas sobre la descolonialidad del poder”, Yuyaykusun № 8. Lima: Universidad Ricardo Palma.

QUIJANO A. (2014a)."Bien vivir: entre el "desarrollo" y la des/colonialidad del poder", en Antología esencial. De la dependencia histórico-estructural a la colonualidad/descolonialidad del poder. Buenos Aires: CLACSO.

QUIJANO A. (2014b). “El'movimiento indígena'y las cuestiones pendientes en A,érica Latina”, en Antología esencial. De la dependencia histórico-estructural a la colonualidad/descolonialidad del poder. Buenos Aires: CLACSO.

RoJAS, J. (2012). Sociedad bloqueada. Movimiento estudiantil, desigualdad y despertar de la sociedad chilena. Santiago: RiL.

\section{8/ ReVISTA de SOCIOLOGÍA 26}


RYFKIN, J. (2014). La sociedad de coste marginal cero. El internet de las cosas y el eclipse del capitalismo. Barcelona: Paidós.

SAndoval, R.; Alonso, J.; De SOUsa, B; CAStells, M; Holloway, J; ZibeChI, R.; GutiérReZ, R.; LóPez y Rivas, G.; EsteVa, G.; MAnero, R.; Rozental, E. y AlmendRA, V. (2015). Pensar desde la resistencia anticapitalista y la autonomía. México: CIESAS.

SARTORI, G. (1998). Homo videns. La sociedad teledirigida. Madrid: Taurus.

SLOTERDIJK, P. (2003). Crítica de la razón cínica. Madrid: Ediciones Siruela.

TAVARES dos SANTOS, J. V. y BARReira, C. (2016). Paradoxos da segurança cidadã. Tomo: Porto Alegre. TODODROV, T. (2014). El espíritu de la ilustración. Barcelona: Galaxia Gutenberg.

UBILLUZ, J. C. (2006). Los nuevos súbditos. Cinismo y perversión en la sociedad contemporánea. Lima: IEP.

WALLERSTEIN, I. (2010). "Latinoamérica y los movimientos antisistémicos", en Toni Negri y otros: I Ciclo de seminarios internacionales. Pensando desde Bolivia. La Paz: Vicepresidencia del Estado Plurinacional de Bolivia.

WRIGHT, E. O. (2014). Construyendo utopías reales. Madrid: Akal.

ZIBECHI, R. (2015). Descolonizar el pensamiento crítico y las prácticas emancipatorias. Bogotá: Ediciones desde abajo. 